\title{
El papel de los mastocitos en la evaluación de la respuesta inflamatoria posoperatoria, al implantar mallas protésicas para la reparación de defectos de la pared abdominal en biomodelos rata Wistar
}

\author{
Alejandro Arboleda C. ${ }^{1}$, Manuel Hernando Franco A. ${ }^{1}$ y Liliana Valladares T. ${ }^{1}$
}

'Biomedical Research Group. Regenerative Medicine and Tissue Engineering Research Incubator. Universidad Icesi. Cl. 18 \#122-135, Cali, Valle del Cauca, Colombia.

Recibido el 4 de julio de 2017 y aceptado para publicación el 23 de agosto de 2017

Correspondencia a: Dra. Liliana Valladares Torres Ivalladares@icesi.edu.co
The role of mast cells in the assessment of postoperative inflammatory response to implanting prosthetic mesh for the repair of abdominal wall defects in Wistar rats

Objective: The objective of this study was to evaluate the role of mast cells in the postoperative inflammatory response after implantation of prosthetic mesh to repair abdominal wall defects in Wistar rat. Materials and Methods: An abdominal wall defect $(30 \times 20 \mathrm{~mm})$ was created in the anterior abdominal wall of 25 adult male Wistar rats. The anatomical defect was then repaired with one of the two type's meshes. Fibroin and monocryl ultrapo prolene meshes. Fibroin meshes were manufactured by weaving its threads, the polypropylene mesh was bought to Johnson \& Johnson-Ethicon. After 28 days of implantation Wistar rats were sacrificed and the mesh with abdominal tissue was extracted. Subsequently the samples were treated with histochemical techniques for histological analysis. Results: The study reported adherence to omentum in both types of meshes used, however, the polypropylene mesh showed widely adhesions to colon, slight to intestine and liver, also in a very lower amount, adhesions to omentum. It was found that mast cells were presented in all the studied regions for the polypropylene mesh (dermis, perimysium, and visceral serosa). Discussion: Studies indicate that mast cells and their products such as histamine, serotonin, and others play a key role in controlling local inflammation, wound healing, adhesions, and reactions to foreign bodies in vivo. Conclusion: We can conclude that this study is a good step to show the possible role of mast cells in the abdominal wall repair process.

Key words: abdominal wall; hernia; repair tissue; mast cells; animal model.

\section{Resumen}

Objetivo: El objetivo de este estudio fue evaluar el papel de los mastocitos en la respuesta inflamatoria posoperatoria tras el implante de mallas protésicas para la reparación de defectos de la pared abdominal en biomodelos rata Wistar. Materiales y Métodos: Se fabricó una malla de fibroína entretejiendo sus hilos. Se utilizaron 25 ratas Wistar macho adultas, a las cuales se les creó un defecto quirúrgico de $30 \times$ $20 \mathrm{~mm}$ en la pared abdominal anterior. Este defecto anatómico fue posteriormente reparado con uno de los dos tipos de mallas previamente esterilizadas, las cuales fueron la malla de fibroína, y la malla comercial ultrapo monocryl prolene composite (Johnson \& Johnson-Ethicon). A los 28 días después del procedimiento quirúrgico se sacrificaron los biomodelos y se extrajeron las muestras que posteriormente fueron tratadas con técnicas histoquímicas para su análisis histológico. Resultados: El estudio reportó adherencia a omento en los dos tipos de malla utilizadas, sin embargo, la malla comercial mostró adherencias de amplio espesor a colon, intestino delgado e hígado, incluyendo también al omento menor. Se encontró que la malla comercial presentaba mayor cantidad de mastocitos en las regiones estudiadas (dermis, perimisio, y la serosa visceral). Discusión: Estudios refieren que los mastocitos y sus productos como la histamina, la serotonina, entre otras juegan un papel clave en el control de la inflamación local, la cicatrización de heridas, adherencias y las reacciones a cuerpos extraños in vivo. Conclusión: Con base en la literatura consultada se puede concluir que el presente estudio es vanguardista en lo que respecta al posible papel que juegan los mastocitos en el proceso de reparación de defectos anatómicos de la pared abdominal. Palabras clave: pared abdominal; hernia; reparación de tejido; mastocitos; modelo animal. 


\section{Introducción}

La hernia se define como la protrusión de las vísceras a través de un anillo herniario; debido a que el peritoneo es distensible se forma un saco herniario ocasionando protrusión del contenido abdominal por el defecto; lo cual desencadena, como efecto mecánico, la dilatación y el crecimiento del anillo herniario ocasionando un defecto anatómico y produciendo alteraciones en la fisiología de la cavidad y la pared abdominal ${ }^{1}$. Este proceso de entrada y salida del contenido abdominal a través de un anillo estrecho, produce inflamación de las vísceras comprometidas, que continuamente rozan con el defecto, generando adherencias entre el saco, los intestinos, el omento y el borde del anillo. Como respuesta al proceso inflamatorio, los mastocitos intervienen favoreciendo la reparación de heridas y las diferentes reacciones a cuerpo extraño $0^{2,3}$; dichas células originadas en la médula ósea, circulan por un tiempo breve en la sangre y después entran al tejido conectivo en el que madura y adquieren sus gránulos característicos. Como células maduras están distribuidas ampliamente en pequeños grupos por el tejido conectivo, en especial cerca de los vasos sanguíneos pequeños, tejido conectivo subepitelial de los sistemas respiratorio y digestivo, y la piel ${ }^{4}$. Su forma y tamaño son variables entre las distintas especies $(20$ a $30 \mu \mathrm{m})$. Los mastocitos son difíciles de observar en tinciones de hematoxilina y eosina, pero se destacan fácilmente con colorantes básicos ${ }^{4}$. Desde el punto de vista morfológico, estas células son grandes, redondas u ovoides y poseen prolongaciones cortas. Tienen el citoplasma lleno de gránulos que se tiñen intensamente y contienen además pequeñas mitocondrias, retículo endoplásmico rugoso y aparato de Golgi poco desarrollado. Su núcleo es esférico, central, eucromático y en ocasiones puede estar cubierto por los gránulos ${ }^{4}$.

La frecuencia de hernias inguinales en la población general es de alrededor del $15 \%$, mientras que la de hernias umbilicales es del $5 \%$, y entre 12 y $15 \%$ de las cirugías abdominales donde se incide la aponeurosis tendrán la posibilidad de desarrollar una hernia incisional ${ }^{1}$. Los índices de recurrencia, a nivel mundial, muestran que del $15 \%$ al $20 \%$ de las hernias inguinales primarias, manejadas mediante técnicas a tensión, recidivan ${ }^{5-7}$. Igualmente se observaron recidivas entre el $25 \%$ al $30 \%$ posterior a herniorrafias inguinales ${ }^{5,6} \mathrm{y}$ en hernias umbilicales se presentó entre el $20 \%$ y el $30 \%{ }^{1}$.

El uso de materiales de malla protésica ha reducido drásticamente la tasa de recurrencia después del proceso de reparación de la hernia ${ }^{8}$. Una malla protésica ideal con un cumplimiento comparable a la de la pared abdominal debe resultar en una mayor comodidad del paciente y una mejor función biomecánica y fisiológica después de la implantación? Cuando se analiza la frecuencia de presentación de una hernia y se relaciona con los índices de recidiva, se concluye que un número muy alto de pacientes presentarán recidiva después de su primera cirugía, lo cual repercute en incapacidad laboral, pérdidas económicas tanto para el paciente que trabaja de manera independiente y tendrá que invertir nuevamente en otra cirugía, así como para las instituciones de salud que tienen que hacer los pagos de incapacidad $\mathrm{y}$ de un nuevo procedimiento quirúrgico ${ }^{1}$.

El polipropileno monofilamento es considerado el material más utilizado, y para muchos autores, el más cercano al ideal. Sin embargo, este y otro tipo de materiales protésicos usados en la actualidad tienden a no permanecer totalmente planos, a desplazarse, arrugarse o enrollarse e incluso a encogerse de tamaño hasta en un $30 \%$ o $40 \%$, cuando no es fijado correctamente, debido a la biomecánica de la región ${ }^{10}$. Si no hay tejido celular subcutáneo, crea adherencias, úlceras y fístulas al estar en contacto directo con los intestinos o la dermis. Igualmente puede ocurrir fistulización a la piel si hay escaso tejido celular subcutáneo y poco crecimiento fibroblástico lo cual impide que se fije con propiedad a la pared abdominal, favoreciendo la aparición de espacios muertos y, por tanto, seromas, hematomas e infecciones tardías, unos más susceptibles que otros, lo que en ocasiones obliga a su remoción ${ }^{10}$.

En este estudio, se utiliza la fibroína extraída de la seda, como material para reparación de defecto anatómico abdominal. La seda es una proteína de origen natural, constituida por polímeros de aminoácidos. Se conocen más de 30.000 especies de arañas y más de 113.000 especies de lepidópteros que producen hilos de seda ${ }^{11}$. Los gusanos de seda pertenecientes a la especie domesticada Bombyx mori; producen seda durante cierta etapa de su ciclo biológico. Sus excelentes propiedades mecánicas, incluyendo elevada resistencia, extensibilidad y absorción de energía en rotura, además de sus características de biocompatibilidad y biodegradabilidad, hacen que sean ampliamente utilizadas y estudiadas para aplicaciones biomédicas ${ }^{12}$. La seda proporciona una excelente combinación de peso ligero $(1,3 \mathrm{~g} /$ $\mathrm{cm}^{3}$ ), alta resistencia (hasta 4,8 GPa como la fibra más fuerte conocida en la naturaleza), la dureza y la elasticidad notable (hasta $35 \%)^{13}$.

Las propiedades mecánicas de los hilos de seda, son superiores en comparación con los hilos de acero y otras fibras artificiales de altas prestaciones. 
Lo verdaderamente asombroso es la combinación de resistencia y deformabilidad: los hilos de acero, o las fibras de altas prestaciones, se rompen con una deformación del 1\% o 2\%; los hilos de seda, en cambio, llegan a superar deformaciones del $30 \%{ }^{11}$. Estas dos propiedades juntas (gran resistencia y deformabilidad) son las que convierten a la seda en un material único, porque permiten que el hilo pueda absorber una gran cantidad de energía antes de romperse. El hilo de gusano de seda (Bombyx mori), con una resistencia alrededor de $600 \mathrm{MPa}$, es capaz de almacenar una energía de $40 \mathrm{KJ} / \mathrm{kg}$, superior a la de las mejores fibras artificiales ${ }^{11}$.

\section{Material y Método}

Para el cumplimiento de los objetivos planteados se contó con el aval y la supervisión del comité de ética de la universidad que proporcionó los biomodelos. Todos los procedimientos experimentales se llevaron de conformidad con la ley 84 del 27 de diciembre de 1989, expedida por el Congreso Nacional Colombiano que adopta el Estatuto Nacional de Protección de los Animales y su uso en actividades científicas.

\section{Tipo de estudio}

Se realizó un estudio experimental, dado que se produjo una manipulación artificial del factor de estudio, en este caso, utilizando mallas protésicas para la reparación de defectos anatómicos creados en la pared abdominal. Para este estudio se usaron grupos de biomodelos rata Wistar, entre los cuales se compararon la malla de fibroína, la malla comercial, y el control sin malla. Es un estudio prospectivo donde los datos se analizaron transcurridos 28 días después del procedimiento quirúrgico

\section{Población y Muestra}

Se utilizaron 25 ratas Wistar macho adultas proporcionadas por el bioterio de la universidad, de 2 meses de edad y una masa corporal de $250 \pm 8 \mathrm{~g}$. Los biomodelos se repartieron para cada grupo experimental: 11 para el grupo de la malla de fibroína, 11 para el grupo de la malla comercial y 3 para el grupo control sin malla.

\section{Fabricación de la malla}

La proteína fibroína se aisló de los capullos de los gusanos de seda Bombyx mori siguiendo el procedimiento estándar de extracción reportado por Rockwood et al. ${ }^{14}$, con leves modificaciones. Los hilos de fibroína se entretejieron manualmente en forma de red.

\section{Estudio Animal/Procedimiento quirúrgico}

Las ratas fueron anestesiadas por inhalación de 1,25 a $2,5 \%$ de isoflurano con $100 \%$ de oxígeno. Se afeitó la pared abdominal ventral y se realizó una desinfección local con Isodine. Los procedimientos se llevaron a cabo en un ambiente estéril. Como antibiótico prequirúrgico se suministró levofloxacina por vía subcutánea a una dosis de $1,2 \mathrm{mg} / \mathrm{kg}$. El procedimiento quirúrgico se basó en una incisión en la piel de $30 \mathrm{~mm}$ de longitud a lo largo de la línea alba, a $20 \mathrm{~mm}$ por encima y por debajo de los genitales y de la apófisis xifoides respectivamente. Posteriormente, se separó la piel de la aponeurosis a nivel de la línea media, proceso xifoideo y genitales considerando una distancia de $10 \mathrm{~mm}$, con respecto a estas estructuras. Se creó un defecto quirúrgico de $30 \times 20 \mathrm{~mm}$ en la pared abdominal anterior que comprendió el plano de los músculos oblicuo externo (OE), oblicuo interno (OI) y transverso del abdomen (TA), además del peritoneo parietal y de la piel. Este defecto anatómico fue posteriormente reparado con uno de los tres tipos de mallas previamente esterilizadas, las cuales fueron la malla de fibroína, otra malla de fibroína con polietilenglicol (Híbrida) y la malla comercial ultrapo monocryl prolene composite (Johnson \& Johnson-Ethicon), con la cual se manejó un grupo de control, conformado por 11 biomodelos de rata Wistar. Se tomó en cuenta también otro grupo de control de 3 biomodelos libres de implante de malla. La malla comercial ultrapo monocryl prolene composite (Johnson \& Johnson-Ethicon) fue elegida como control en el estudio debido a que ha sido utilizada ampliamente en la reparación clínica de la pared abdominal.

Las mallas de $30 \times 20 \mathrm{~mm}$ se implantaron a los bordes del defecto herniario, en posición retromuscular y preperitoneal, en contacto directo con el omento mayor y las vísceras peritoneales, utilizando sutura estéril absorbible Vycril plus antibacterial 2-0 Ethicon, mediante puntos separados. Se realizó cierre de la piel mediante puntos separados con sutura no absorbible seda estéril 2-0 Ethicon. Para manejo del dolor posquirúrgico, se suministró inmediatamente después de la cirugía $177,8 \mathrm{mg} / \mathrm{kg}$ de dipirona y 3,2 $\mathrm{mg} / \mathrm{kg}$ de morfina. Los animales se recuperaron de la anestesia bajo una lámpara de calor y fueron devueltos a sus jaulas en el bioterio para cuidado de la herida y vigilancia de la evolución posquirúrgica.

\section{Tratamiento posoperatorio, los efectos adversos y las complicaciones posoperatorias}

Después de la cirugía, los animales fueron devueltos a sus jaulas con collar isabelino y sometidos 
a revisiones periódicas para valorar el estado de la herida quirúrgica. Durante los dos días posteriores se realizó limpieza alrededor de la herida con jabón neutro y se suministró levofloxacina subcutánea a una dosis de $6,0 \mathrm{mg} / \mathrm{kg}$, para el tratamiento del dolor se suministró $177,8 \mathrm{mg} / \mathrm{kg}$ de dipirona cada $6 \mathrm{~h}$ y $3,2 \mathrm{mg} / \mathrm{kg}$ de morfina cada $4 \mathrm{~h}$

\section{Evaluación de adherencias}

Inmediatamente después del sacrificio del biomodelo, se abrió la sutura y se evaluó la cavidad peritoneal. La formación de adherencias se determinó por la presencia o ausencia de las vísceras abdominales unidas al sitio del implante de malla (omento, colon, intestino delgado e hígado).

\section{Histología}

Las muestras de tejido se prepararon y embebidos en parafina. Los bloques de parafina se seccionaron a un espesor de 5 micras y se realizó tinción elástica de Hart y Van-Giesson. Las secciones teñidas se visualizaron bajo un microscopio óptico en campos de alto poder $40 \mathrm{X}$, en la región de la dermis, aponeurosis, perimisio y la serosa visceral. Todas las muestras se sometieron a cuantificación ciega por un observador independiente, el cual realizó el conteo de mastocitos de izquierda a derecha, alrededor de vasos sanguíneos, repartidos en 10 áreas por región.

\section{Análisis estadístico}

Los valores obtenidos en las distintas mediciones fueron procesados con el programa estadístico SPSS versión 19.0 (EE.UU.) con un nivel de significancia de 0,05 . Para la cantidad de mastocitos, se estimaron medidas de tendencia central y de dispersión, con un intervalo de confianza del 95\%. Para comparar las medias entre los diferentes grupos y la comprobación de si existen diferencias significativas, se realizó el análisis de varianza de un factor (ANOVA). Posteriormente se realizó la prueba de Duncan para comparar todos los pares de medias.

\section{Resultados}

\section{Observaciones posoperatorias}

Para el grupo de la malla de fibroína, todas las heridas se curaron, no se observaron signos de infección o rechazo en la ubicación del implante durante el período de 28 días del experimento, ni complicaciones posoperatorias.

En el grupo de la malla comercial ultrapo monocryl prolene composite (Johnson \& Johnson-Ethicon), se presentaron dos casos de eventración a los tres y siete días posteriores a la cirugía respectivamente, además de aparición de fístula intestinal por lo cual fue necesario sacrificarlos. Se presentó un caso en el cual el biomodelo falleció diez días posteriores a la cirugía, se llevó a cabo laparotomía exploratoria encontrándose cambios macroscópicos compatibles con infección de cavidad (Figura 1).

\section{Adherencias}

Para la malla de fibroína se observaron adherencias a omento mayor sin observarse este comportamiento con el resto de los órganos de la cavidad abdominal. Mientras que con la malla comercial fueron evidentes adherencias a colon, intestino delgado e hígado, incluyendo también al omento menor (Figura 2).

\section{Análisis histológico}

A continuación se determinaron entre cuales tipos de malla se dan esas diferencias significativas, para

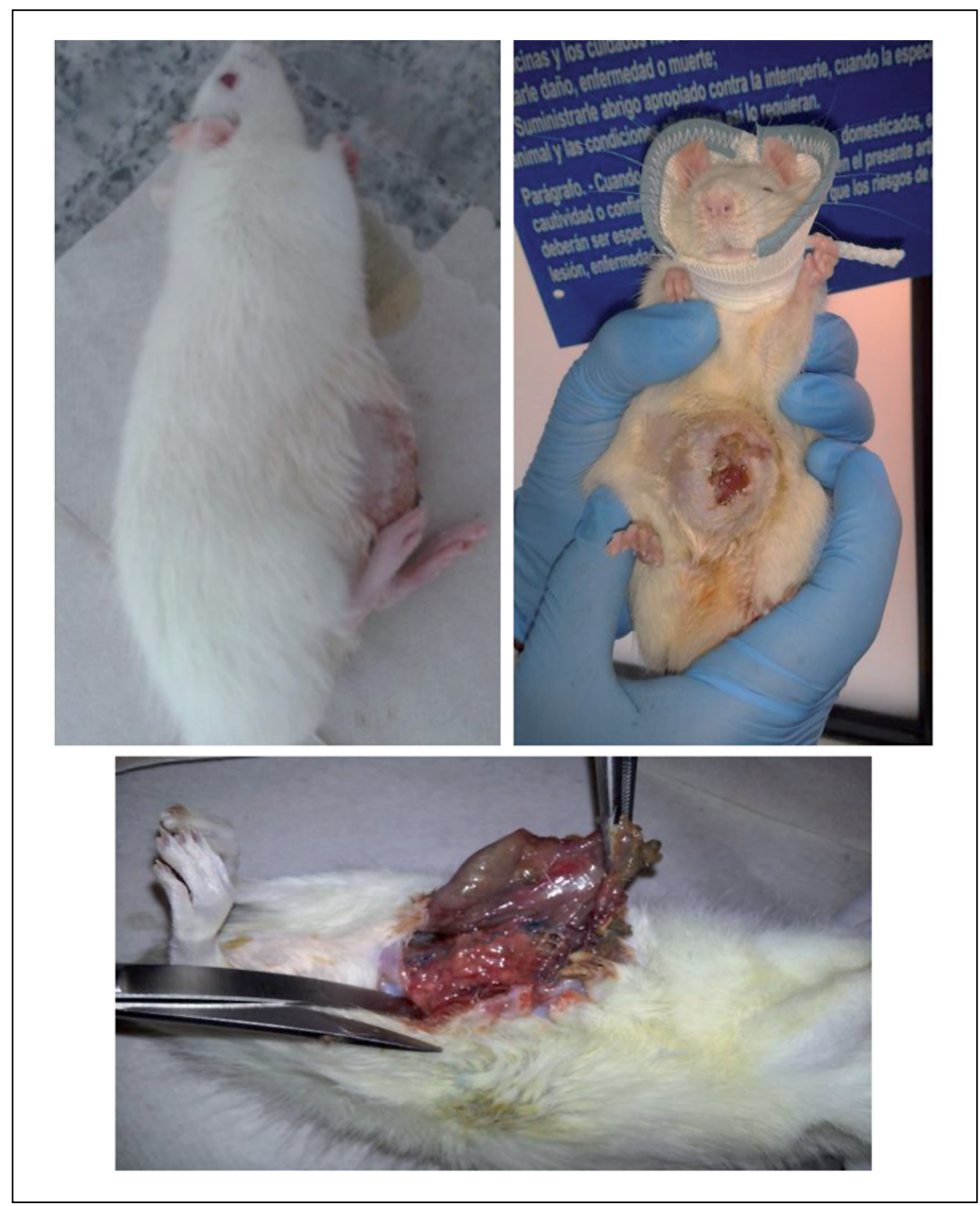

Figura 1. Eventración del biomodelo reparado con la malla comercial. 


\section{ARTíCULO ORIGINAL}

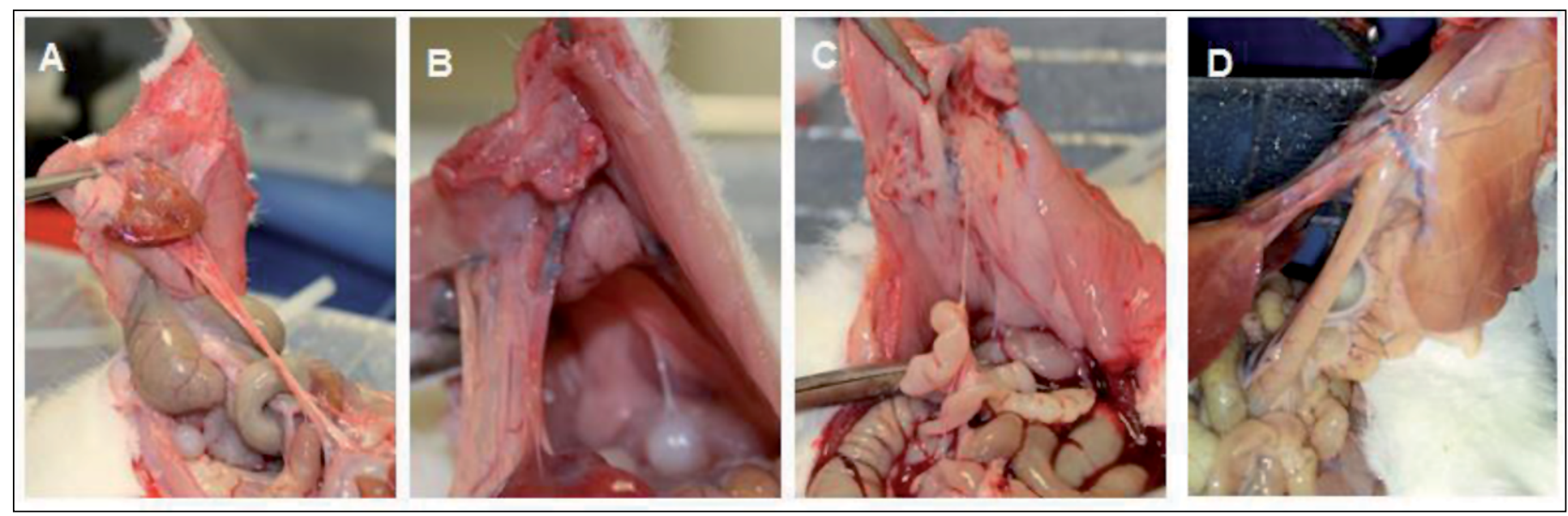

Figura 2. Adherencias para la malla comercial ultrapo monocryl prolene composite (Johnson \& Johnson-Ethicon). A: Hígado y colon; B: Omento; C: Intestino delgado; D: Intestino delgado, hígado y omento.

Tabla 1. Subconjuntos homogéneos para la cantidad promedio de mastocitos según región de lectura y tipo de malla

\begin{tabular}{|c|c|c|c|c|c|c|c|c|}
\hline \multirow[t]{2}{*}{ Tipo de malla } & \multirow[t]{2}{*}{$\mathbf{n}$} & \multicolumn{2}{|c|}{$\begin{array}{c}\text { Dermis } \\
\text { Subconjunto } \\
\alpha=\mathbf{0 , 0 5}\end{array}$} & \multirow{2}{*}{$\begin{array}{c}\text { Aponeurosis } \\
\text { Subconjunto } \\
\alpha=\mathbf{0 , 0 5} \\
1\end{array}$} & \multicolumn{2}{|c|}{$\begin{array}{c}\text { Perimisio } \\
\text { Subconjunto } \\
\alpha=\mathbf{0 , 0 5}\end{array}$} & \multicolumn{2}{|c|}{$\begin{array}{c}\text { Serosa visceral } \\
\text { Subconjunto } \\
\alpha=\mathbf{0 , 0 5}\end{array}$} \\
\hline & & 1 & 2 & & 1 & 2 & 1 & 2 \\
\hline Control sin malla & 30 & 6,23 & & 3,83 & 1,70 & 1,70 & 2,13 & \\
\hline Comercial & 80 & & 8,34 & 3,50 & 1,55 & 1,55 & & 4,97 \\
\hline
\end{tabular}

lo cual se utilizó, la prueba de Rangos Múltiples de Duncan (Tabla 1).

Basado en la prueba de Duncan, en la región de la dermis, las medias, de los grupos de fibroína $\overline{\mathrm{x}}=6,06$ y control $\sin$ malla $\overline{\mathrm{x}}=6,23$, fueron iguales, es decir que no son significativas las diferencias que se puedan dar. Contrario sucede para la comercial y la de fibroína, donde sí hay diferencias significativas entre sus medias $(\overline{\mathrm{x}}=8,34$ y $\overline{\mathrm{x}}=6,06$ respectivamente). Para la región de la aponeurosis no hay diferencias significativas en las medias para ningún grupo, es decir que sólo existe un subconjunto homogéneo formado por todos los grupos. En la región del perimisio, no hay diferencias significativas en las medias de la cantidad de mastocitos para los grupos control sin malla, comercial y fibroína $(\bar{x}=1,70$, $\overline{\mathrm{x}}=1,55$ y $\overline{\mathrm{x}}=1,38$ respectivamente). Finalmente, para la región de la serosa visceral, se encontró que hay diferencias significativas en la cantidad de mastocitos entre el control sin malla y los otros grupos.

\section{Discusión}

Orestein et al (2010), refieren que los mastocitos y sus productos como la histamina, la serotonina, la heparina, las prostaglandinas, las citoquinas, entre otras juegan un papel clave en el control de la inflamación local, la cicatrización de heridas y las reacciones a cuerpos extraños in vivo ${ }^{2}$. En su estudio relacionado con los efectos de la modulación de los mastocitos sobre la respuesta del huésped en el implante de malla sintética, argumentaron que los mastocitos desempeñaban papeles importantes en reacciones tejido-huésped inducida por la malla. El bloqueo de la degranulación de los mastocitos disminuyó la inflamación temprana y la fibrosis inducida por la mayoría de mallas sintéticas en este estudio $^{2}$. En este estudio se encontró que la malla comercial presentaba mayor cantidad de mastocitos en las regiones estudiadas (dermis, perimisio y la serosa visceral). 
Orestein et al. manifestaron que la acumulación de mastocitos fue visto en la periferia de las reacciones inflamatorias, y en asociación con la fibrosis y la neovascularización inducida por malla. Se ha propuesto que el tratamiento con Cromolín ha producido una disminución significativa de las respuestas fibróticas al tipo de malla utilizado. Así mismo, han concluido que la supresión de los mastocitos pueden conducir a una reducción en las reacciones de los tejidos que rodean los implantes de malla sintética ${ }^{2}$. En el estudio actual, se encontró que no presentaban diferencias significativas en las medias de la cantidad de mastocitos entre la malla de fibroína y el grupo control al cual no se le implantó malla, en la región de la dermis, aponeurosis y perimisio. En contraste la malla comercial si presentó diferencias significativas en la dermis.

Tang et al (1998), manifestaron que dentro de los mediadores de la inflamación, es la histamina la que más se ha relacionado con la activación del mecanismo de diapédesis de las células inflamatorias y la posterior adhesión a los implantes de biomateriales ${ }^{3}$.

Tcacencu et al (2008), han relacionado la presencia, a largo plazo, de los mastocitos en el sitio de implantación con el grado de encapsulación fibrótica ${ }^{15}$. Sin embargo, el efecto potencial de los mastocitos y los factores de degranulación sobre las respuestas fibróticas de los tejidos periféricos a los implantes aún no se ha sido demostrado.

Thevenot et al (2011), plantearon la hipótesis de que la activación de los mastocitos está directamente asociados con la patogénesis fibrótica de los implantes de los biomateriales ${ }^{16}$. Para modelar la formación de tejido fibrótico mediada por el implante, se emplearon las películas hechas de poli-L de ácido glicólico (PLGA), materiales comúnmente utilizados para la fabricación de andamios de ingeniería de tejidos. Algunos de estos implantes fueron hechos para lanzar una variedad de bloqueadores de la histamina, estabilizador de los mastocitos o activador ${ }^{16}$. Así, estos resultados indicaron que la interacción con el biomaterial inicial que resultó en la estimulación de las células cebadas y los subproductos de degranulación no sólo estimularon la cascada inflamatoria. Al utilizar la malla de fibroína sintetizada en este estudio, no se presentaron casos de signos de infección o rechazo al biomaterial en el sitio de implante, durante el tiempo designado como posoperatorio; podría asumirse que la baja frecuencia de mastocitos en los diferentes planos de la pared abdominal, superficial, medio y profundo, da resultados positivos en la recuperación y biocompatibilidad con el tejido huésped.

Dubay et al (2007), manifestaron que la repara- ción de la hernia incisional, puede estar asociada con el aumento en la rigidez en la pared abdominal, debido a la fibrosis y atrofia, lo que resulta en un desprendimiento del implante del tejido huésped, dado por la presión intraabdominal produciendo retracción de la musculatura, ocasionando recidiva del defecto herniario ${ }^{17}$. En el estudio realizado, se presentaron dos casos de eventración después de 3 y 7 días posteriores al implante de malla comercial; considerando que la presencia de mastocitos, en estos dos casos, estuvo en una proporción mayor o igual con respecto a la muestra estudiada y debido a una posible degranulación de mediadores, contribuyó a la generación de tejido fibrótico observándose en la necropsia cambios compatibles con fibrosis, ocasionando rigidez en el sitio de implante, limitando la movilidad de la pared abdominal; lo que muy probablemente causó, dado su presión intraabdominal, una recidiva.

El dolor posoperatorio es una forma común de dolor agudo. Varios estudios han indicado que la analgesia posoperatoria efectiva reduce la morbilidad después de la cirugía, lo que mejora los resultados del paciente y reduce los gastos clínicos ${ }^{18}$ Un conocimiento adecuado sobre el tratamiento del dolor posoperatorio es importante para reducir la morbilidad y la mortalidad de los pacientes después de la cirugía ${ }^{19,20}$. Sin embargo, estudios recientes han demostrado que alrededor del 50-70\% de los pacientes experimentan dolor moderado a severo después de la cirugía, lo que indica que a pesar del desarrollo de nuevos medicamentos y la mejora de las técnicas analgésicas, el dolor posoperatorio sigue siendo poco evaluado y mal tratado ${ }^{20}$.

Oliveira et al. (2011) $)^{18}$ y Yasuda et al. (2013), demostraron que la degranulación de los mastocitos está implicado en el desarrollo del dolor posoperatorio y puede ser inducida por una incisión quirúrgica. Ellos demostraron que la estabilización de los mastocitos provoca un efecto antinociceptivo en un modelo de dolor posoperatorio en ratón. Lograron disminuir los niveles de los mediadores de los mastocitos después de su degranulación, como la histamina y la serotonina, reduciendo la nocicepción posoperatorio; lo que indica que la activación de mastocitos es esencial para el desarrollo del dolor posoperatorio.

Oliveira et al. (2011) $)^{18}$, observaron histológicamente que después de la cirugía, había una alta degranulación de los mastocitos en la piel con la lesión. Hallazgos similares fueron encontrados por Weller et al. (2006) ${ }^{21}$, quienes demostraron que la mayoría de los mastocitos de la piel adyacentes a una herida muestran alta degranulación. Después del 
procedimiento quirúrgico, también se observó que hubo un incremento en los niveles de serotonina y la histamina en la muestra perfundida, lo que indicó que la lesión produjo una pronta liberación de mediadores de mastocitos ${ }^{18}$.

Para apoyar la idea de que este tipo de célula está implicada en la nocicepción inducida por una incisión, Oliveira et al. trataron a los animales con cromoglicato de sodio antes de la cirugía ${ }^{18}$. El cromoglicato protege las membranas de los mastocitos, lo que obstaculiza su degranulación ${ }^{22}$. De acuerdo con los resultados obtenidos a partir de la disminución de mastocitos, el pretratamiento con cromoglicato era capaz de reducir la nocicepción y evitar un aumento en los niveles de histamina y serotonina inducidas por la lesión quirúrgica ${ }^{18}$. Es importante obtener una mejor comprensión de los eventos celulares que controlan los mecanismos periféricos del dolor posoperatorio. Lo anterior nos lleva a replantear la posibilidad de suministrar inhibidores de mastocitos como alternativa en el manejo del dolor.

\section{Conclusiones}

Con base en la literatura consultada se puede concluir que el presente estudio es vanguardista en lo que respecta al posible papel que juegan los mastocitos en el proceso de reparación de defectos anatómicos de la pared abdominal.

Una mejor comprensión del papel que juegan los mastocitos en reacciones tisulares inducidas por malla, favorecería la creación de nuevos enfoques terapéuticos que permitan mejorar la biocompatibilidad del biomaterial y en última instancia mejorar los resultados clínicos en pacientes sometidos a una reparación de hernia con biomateriales sintéticos

En el modelo propuesto, la fibroína mostró tener un mejor comportamiento histológico, pues presentó menor cantidad de mastocitos con respecto a la malla comercial.

La fibroína podría considerarse como un material prometedor para el desarrollo de biomateriales para la reparación y/o regeneración funcional de hernias de la pared abdominal, capaz de modular una respuesta biológica del tejido receptor.

\section{Responsabilidades éticas}

Protección de personas y animales. Los autores declaran que los procedimientos seguidos se conformaron a las normas éticas del comité de experimentación humana responsable y de acuerdo con la Asociación Médica Mundial y la Declaración de Helsinki.

Confidencialidad de los datos. Los autores declaran que en este artículo no aparecen datos de pacientes.

Derecho a la privacidad y consentimiento informado. Los autores declaran que en este artículo no aparecen datos de pacientes.

\section{Financiación}

Este trabajo fue apoyado por la Universidad Icesi.

\section{Conflicto de intereses}

Los autores certifican que no tienen conflicto de intereses o conflictos financieros para divulgar.

\section{Agradecimientos}

Agradecemos al personal de Bioterio Universidad Icesi, Osibar Jamauca Yanguatin, Jorge Enrique Calero Giraldo y Dr. Gabriel J. Echeverri, por su asistencia en el primer procedimiento quirúrgico. También queremos agradecer al profesor Oscar Tamayo que nos asesoró en el análisis histológico.

\section{Bibliografía}

1. Mayagoitia González JC. Hernioplastía sin tensión. In Aldrete Velasco J, editor. Hernias de la pared abdominal. Tratamiento actual. México, D.F: Alfil; 2009. p. 21-30.

2. Orenstein S, Saberski E, Klueh U, Kreutzer D. Effects of mast cell modulation on early host response to implanted synthetic meshes. Hernia 2010;14:511-6.

3. Tang L, Jennings T, Eaton J. Mast cells mediate acute inflammatory responses. Proc Natl Acad Sci USA 1998;95:8841-6.

4. Sepúlveda Saavedra J. Capítulo 5 Tejido conectivo. In García Carbajal NL, editor. Texto atlas de histología biología celular y tisular. México, D.F: Mc Graw Hill; 2012. p. 83-98.

5. Rutkow I, Robbinas A. Aspectos demográficos, de clasificación y socioeconómicos en la reparación de hernia en Estados Unidos. Clin Quir NA. 1993;3:443-57.

6. Rutkow I. Aspectos epidemiológicos, económicos y sociológicos de la cirugía 
de hernia en Estados Unidos, en el decenio de 1990. Clin Quir NA. 1998; 6(1):889-917.

7. Mayagoitia G, Suárez F, Cisneros M. Hernioplastía inguinal tipo Lichtenstein. Cir Gral. 2000; 22(4):329-33.

8. Luijendijk R, Hop W, van den Tol M, de Lange D, Braaksma M, IJzermans J, et al. A comparison of suture repair with mesh repair for incisional hernia. N Engl J Med. 2000;343(6):392-8

9. Konerding M, Chantereau P, Delventhal V, Holste J, Ackermann M. Biomechanical and histological evaluation of abdominal wall compliance with intraperitoneal onlay mesh implants in rabbits: a comparison of six different state-of-the-art meshes. Med Eng Phys. 2012;34(7):806-16.

10. Abraham Arap JF. Material a utilizaren la reparación de las hernias. In Castro López FW, editor. Cirugía de las hernias de la pared abdominal. La Habana: Ciencias Médicas; 2010. p. 249-80.

11. Elices M, Pérez Rigueiro J, Plaza GR, Guinea G. Usos médicos de la seda. Investigación y Ciencia. 2011; 419(1): 8-35.

12. Wang Y, Kim H, Vunjak-Novakovic G, Kaplan D. Stem cell-based tissue engineering with silk biomaterials. Biomaterials. 2006; 27(36):6064-82.

13. Rising A, Nimmervoll H, Grip S, Fernández-Arias A, Storckenfeldt E,
Knigh TD, et al. Spider silk proteinsmechanical property and gene sequence. Zoolog Sci. 2005 March; 22(3): p. 273281.

14. Rockwood DN, Preda RC, Yücel T, Wang X, Lovett ML, Kaplan DL. Materials fabrication from Bombyx mori silk fibroin. Nat Protoc. 2011;6(10):1612-31.

15. Tcacencu I, Wendel M. Collagenhydroxyapatite composite enhances regeneration of calvaria bone defects in young rats but postpones the regeneration of calvaria bone in aged rats. J Mater Sci Mater Med. 2008;19(5):2015-21.

16. Thevenot P, Baker D, Weng. H, Sun M, Tang L. The pivotal role of fibrocytes and mast cells in mediating fibrotic reactions to biomaterials. Biomaterials. 2011; 32(33):8394-403.

17. DuBay D, Choi W, Urbanchek M, Wang $\mathrm{X}$, Adamson B, Dennis R, et al. Incisional herniation induces decreased abdominal wall compliance via oblique muscle atrophy and fibrosis. Ann Surg. 2007; 245(1):140-6.

18. Oliveira SM, Drewes CC, Silva CR, Trevisan G, Boschen SL, Moreira CG, et al. Involvement of mast cells in a mouse model of postoperative pain. Eur J Pharmacol. 2011;672(1-3): 88-95.

19. Kehlet H, Jensen TS T, Woolf C. Persistent postsurgical pain: risk factors and prevention. Lancet. 2006;367(9522):1618-25.

20. Pogatzki-Zahn E, Zahn P, Brennan T. Postoperative pain-clinical implications of basic research. Best Pract Res Clin Anaesthesiol. 2007; 21(1):3-13.

21. Weller K, Foitzik K, Paus R, Syska W, Maurer M. Mast cells are required for normal healing of skin wounds in mice. FASEB J. 2006; 20(13):2366-8.

22. Parada CA, Tambeli $\mathrm{CH}$, Cunha FQ, Ferreira SH. The major role of peripheral release of histamine and 5-hydroxytryptamine in formalin-induced nociception. Neuroscience. 2001; 102(4):937-44.

23. Rath A, Chevrel J. The healing of laparotomies; a bibliographic study. Part Two: Technical aspects. Hernia. 2000;4(1):41-8.

24. Mayagoitia G. Acceso anterior para hernioplastía lumbar posincisional. Cir Gen. 2001;23(1):33-5.

25. Stoppa R, Ralaimiaramanana F, Henry X, Verhaeghe P. Evolution of large ventral incisional hernia repair. The French contribution to a difficult problem. Hernia. 1999;3(1):1-3.

26. Pineda Ayala MLE. Capítulo 5. Distribuciones de probabilidad normal. In Pineda Ayala MLE. Probabilidad y estadística. México: Pearson Educación; 2004. p. 259. 